\title{
Artículos
}

\section{Análisis de la localización de la oferta restaurantera del destino turístico Varadero, Cuba}

\author{
Análise da localização da oferta do restaurantes no destino turístico \\ Varadero, Cuba
}

\section{Location analysis of restaurants in the tourist destination Varadero, Cuba}

\author{
Yadrián Arnaldo García Pulido ${ }^{1}$, Ismaray Rodríguez Bello ${ }^{1}$, Roberto Argelio Frías Jiménez ${ }^{1}$ \\ ${ }^{1}$ Universidad de Matanzas, Cuba.
}

Palabras clave:

Localización,

Distribución;

Servicios gastronómicos;

Planificación turística.

Palavras-chave:

Localização;

Distribuição;

Serviços gastronômicos;

Planejamento turístico.

Keywords:

Location,

Distribution;

Gastronomic services;

Tourism planning;

Revisado por pares.

Recibió en: 07/08/2020.

Aprobado en: 27/10/2020.
Resumen

Entre los principales destinos de sol y playa de Cuba, se encuentra Varadero donde una adecuada planificación de los servicios que se ofertan, resulta vital para su gestión. La creciente variedad de ofertas gastronómicas en sus 22 km de extensión, no está cumpliendo con las expectativas de los clientes por razones como la deficiente localización no solo en el plano, sino también de acuerdo al tipo de oferta que brindan. La presente investigación tuvo como objetivo analizar la localización de los servicios gastronómicos del destino turístico Varadero. Para el desarrollo del trabajo se realizó una amplia revisión documental, entrevistas a los administrativos de los restaurantes y el empleo de sistemas de información geográfica y análisis clúster. El análisis de los 43 restaurantes en operación en el Varadero histórico evidenció una concentración de 10 establecimientos por kilómetro cuadrado. Se detectaron 11 centroides donde los restaurantes se encuentran a menos de 100 metros, siendo el rango de distancia mayoritario de 30 a 200 metros. Se evidenció un significativo desbalance tanto en la localización como en la oferta de las instalaciones en el área, con una clara incidencia en la percepción de variedad del destino, and impact, followed by Spain.

Resumo

Entre os principais destinos de sol e praia em Cuba fica Varadero, onde o planeamento adequado dos serviços oferecidos é vital para a sua gestão. A crescente variedade de ofertas gastronómicas nos seus 22 km de extensão, não está a satisfazer as expectativas dos clientes por razões como a localização deficiente não só no mapa, mas também de acordo com o tipo de oferta que estes oferecem. $O$ objectivo desta investigação consistiu em analisar a localização dos serviços gastronómicos no destino turístico de Varadero. Para o desenvolvimento do trabalho, foi realizada uma extensa revisão documental, entrevistas com os administradores dos restaurantes e a utilização de sistemas de informação geográfica e análise de clusters. A análise dos 43 restaurantes em funcionamento no histórico Varadero mostrou uma concentração de 10 estabelecimentos por quilómetro quadrado. Foram detectados onze centróides onde os restaurantes se situam a menos de 100 metros de distância, com o alcance maioritário a ser de 30 a 200 metros. Houve um desequilíbrio significativo tanto na localização como no fornecimento de instalações na área, com um claro impacto na percepção da variedade do destino.

\section{Abstract}

The main sun and beach destinations in Cuba is Varadero, an adequate planning of the services offered is vital for its management. The growing variety of gastronomic offerings in its $22 \mathrm{~km}$ of extension, is not meeting the expectations of customers, for reasons such as the deficient location not only in the plan, but also according to the type of offerings that provide. The objective of this research was to analyze the location of gastronomic services in the Varadero tourist destination. For the development of the work, an extensive documentary review was carried out, interviews with the restaurant managers and the use of geographic information systems and cluster analysis. The analysis of the 43 restaurants in operation in the historic Varadero showed a concentration of 10 establishments per square kilometer. Eleven centroids were detected where the restaurants are located less than 100 meters away, where the majority range being from 30 to 200 meters. There was a significant 
Editor:

Glauber Eduardo de Oliveira Santos imbalance in the location and in the supply of facilities in the area, with a clear impact on the variety perception of destination.

Cómo citar: Pulido, Y. A. G.; Bello, I. R.; Jiménez, R. A. F. (2021). Análisis de la localización de la oferta restaurantera del destino turístico Varadero, Cuba. Revista Brasileira de Pesquisa em Turismo, São Paulo, 15 (3), e-2215, Sep./Dic. http://dx.doi.org/10.7784/rbtur.v15i3.2215

\section{INTRODUCCIÓN}

Debido a la complejidad de los destinos turísticos resulta imprescindible la realización de una adecuada planificación (Diéguez Matellán, 2008), para optimizar la rentabilidad de los recursos, ofrecer un esquema equitativo de costes y beneficios, maximizar la satisfacción del turista y desarrollar las pautas para que su desarrollo vaya de la mano de los intereses de sus habitantes. Transformar un destino para que pueda ser competitivo ante los avances de otros y tomar en cuenta sus debilidades para cubrir los vacíos que haya, es parte de los trabajos de planificación, pero sobre todo del seguimiento de los planes en ejecución (Medina Argueta y Rosado Varela, 2014).

De acuerdo con Toro et al. (2015) si bien la planificación no define el éxito de un destino turístico, sí aumenta las posibilidades de dar en el blanco, a diferencia de estar dando pasos a ciegas. Entender la planificación turística desde el punto de vista de la intervención integral en el destino permite entender el desarrollo de un modo amplio, e ir más allá de la cuenta de resultados de un único sector.

Entre los destinos turísticos cubanos destaca Varadero por ser la principal oferta de sol y playa, con una cuota de mercado alrededor de un 42 \% del turismo que arriba al país según la ONEI (2020). Situado al occidente de la isla y en la costa norte (figura 1), pertenece a la provincia de Matanzas y se encuentra a $140 \mathrm{~km}$ de La Habana (capital del país), la península de Hicacos abarca $22 \mathrm{~km}$ de playas que se favorecen por las aguas cálidas del mar Caribe. Su explotación intensiva comenzó en la década de los 90 y continúa incrementándose su planta habitacional.

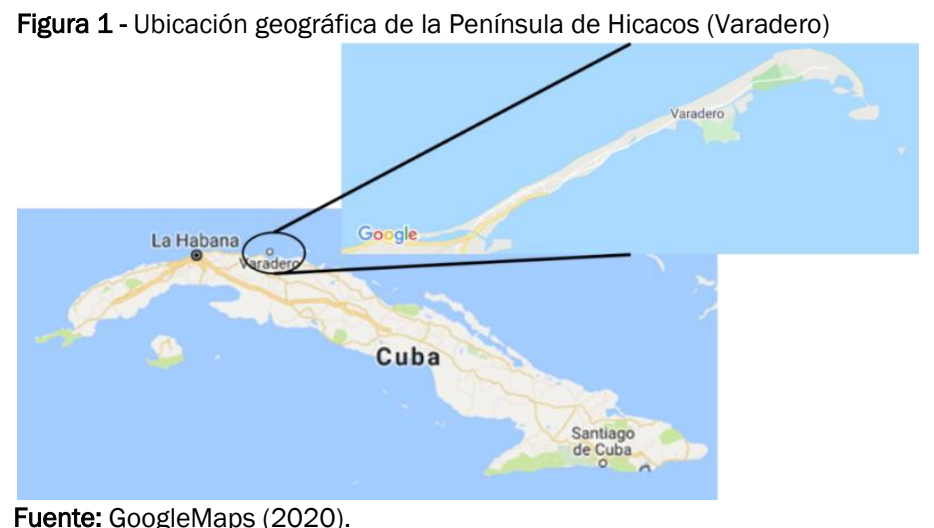

Varadero como destino turístico, cuenta con restaurantes que forman parte de la composición de la oferta extra hotelera. Hasta el 2016, contaba con un total de 30 restaurantes estatales. De ellos el $36 \%$ responde a restaurantes especializados, el $46 \%$ a restaurantes de comida internacional y el $16 \%$ a los restaurantes que tienen como oferta la comida criolla. Como se puede apreciar, no existía gran cantidad de restaurantes a los que el turista pudiera sentirse motivado para comer. La oferta no era suficiente además, solo el $16 \%$ del total corresponde a restaurantes de comida tradicional cubana. En 2016 se aprueba la apertura de negocios privados para aumentar la competitividad del destino (PCC, 2016).

Con esta aprobación, Varadero comienza la apertura de servicios gastronómicos no estatales. Hoy cuenta con 13 restaurantes privados, para un total de 43 en el destino. Esto ha propiciado un aumento de la oferta restaurantera que a nivel de país aporta el $41,1 \%$ de los ingresos asociados al turismo (ONEI, 2020), pero no de la variedad, dado que la mayoría son de comida internacional.

Sin embargo, de acuerdo con Velazco (2016) la planificación ha sido deficiente en el destino a la hora de abrir estos restaurantes y posicionarlos acorde a la oferta que realizan en el espacio geográfico, trayendo como resultado la concentración de servicios en determinadas zonas. 
Al respecto, se aprecia una concentración de restaurantes en las zonas comprendidas entre la Autopista Sur hasta la calle 40 , representando el $51 \%$ del total de restaurantes. La zona enmarcada desde la calle 40 hasta la 20 , posee el 25 \% y en menor concentración, la zona que se extiende desde la calle 20 hasta el Reparto Kawama con un $23 \%$ del total de los restaurantes (figura 2). Esta situación ha provocado la descomercialización de restaurantes y carencia de insumos necesarios para su operación debido a la similitud de ofertas, de acuerdo con entrevistas sostenidos con la administración de Palmares S.A, empresa dedicada a gestionar la gastronomía en el destino.

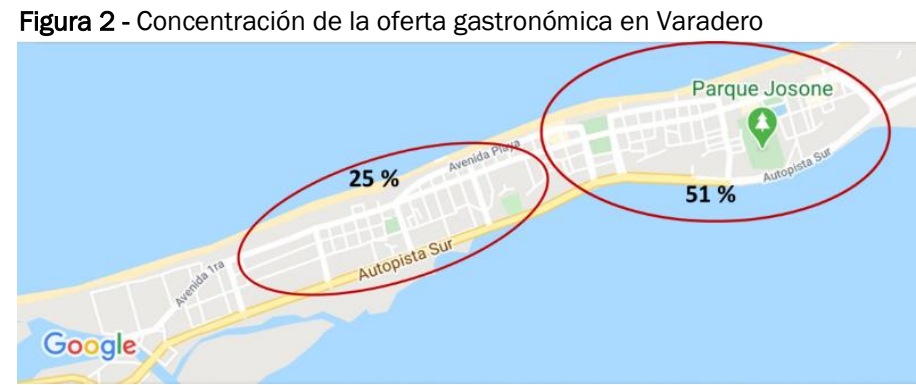

Fuente: Elaboración propia.

Ante la deficiente planificación en oferta y localización de los servicios gastronómicos, la investigación se propuso analizar la distribución de la oferta de restauración del destino Varadero.

\section{ANTECEDENTES}

\subsection{Modelos de planificación de destinos turísticos}

Para Cooper y Fletcher (2003) un destino turístico está dado por un conjunto de componentes, enclavados en: a) Atracciones: motivos de la visita al destino, pudiendo ser características naturales, artificiales o eventos; b) Amenidades $u$ otros servicios e instalaciones de apoyo distintos a las atracciones; c) Accesos: por una parte el desarrollo y mantenimiento de vínculos de transporte eficientes con los mercados emisores y por otro el transporte en el propio destino y d) Ancillary services: aquellos servicios prestados al turista y al sector turístico a través de las organizaciones locales de turismo.

Por su parte, Tooth (2014) lo define bajo el prisma de la oferta, como la combinación de diferentes elementos, a través de los que se intenta ofrecer una experiencia integrada a los turistas reducidos tradicionalmente a zonas bien definidas geográficamente (país, isla, ciudad, pueblo). Es un área que presenta características reconocidas por los visitantes potenciales, las cuales justifican su consideración como entidad y atraen viajes al mismo, con independencia de las atracciones que existan en otras zonas.

De acuerdo con Joseph A Ivars (2003) se pueden identificar cuatro enfoques con relación a la planificación turística: desarrollista, económico, físico y comunitario. El desarrollista, refiere la tradición dominante de la planificación turística y se caracteriza por tener una posición favorable y acrítica del turismo. El económico, concibe al turismo como actividad exportadora, con potencial contribución para el crecimiento económico, el desarrollo regional y la reestructuración productiva; otorga prioridad a los fines económicos por sobre los ambientales y sociales sin analizar cómo se distribuyen socialmente los beneficios del turismo. El físico incorpora la dimensión territorial para alcanzar una adecuada distribución de las actividades turísticas en el espacio y lograr usos racionales del suelo y examina los aspectos ambientales. El comunitario promueve un control local del desarrollo turístico con el fin de que la población sea la beneficiada, haciendo énfasis en desarrollos de abajo-arriba.

A lo largo de la historia, tanto autores como instituciones, han diseñado diferentes modelos de planificación turística: Lawson y Baud-Bovy (1977), Kaiser Jr y Helber (1983), Hernández Díaz (1985), Pearce y Soriano Bello (1988), Bote Gómez (1990), Godfrey y Clarke (2000), Gunn (2002), Zamorano Casal (2002), Josep A. Ivars (2003), Boullón (2006), Vera Rebollo y Baños Castiñeira (2010), Duarte Pimentel (2016) y Molina Rodríguez (2019).

Los modelos de Hernández Díaz (1985) y Molina Rodríguez (2019) responden al enfoque desarrollista. Ambos encaminados a contribuir al desarrollo nacional y regional mediante la actividad turística. Aunque estos modelos apuntan hacia propuestas integrales, sus alcances resultaron limitados operativamente.

Los modelos de Kaiser Jr y Helber (1983) y Bote Gómez (1990) poseen un enfoque económico. Mediante estos, la forma de hacer turismo permite la activación económica y la generación de empleos, pero también genera impactos 
económicos, ambientales y culturales negativos en los espacios turísticos locales, a través de la elaboración de planes maestros.

El enfoque espacial, también llamado urbanístico o físico, ha sido uno de los más prolíferos en la planificación turística. El modelo propuesto por Boullón (2006) realiza un análisis del entorno físico así como de la rentabilidad económica para elaborar el plan de desarrollo físico. Pearce y Soriano Bello (1988), reflejan la identificación de las áreas de desarrollo potenciales como punto clave para el proceso.

Los modelos de Lawson y Baud-Bovy (1977), Vera (1997) y Zamorano (2002) están concebidos como el instrumento adecuado para llevar a cabo la detección, organización y coordinación del desarrollo turístico sustentable, bajo un enfoque participativo de las comunidades locales, incorporando la atención a aspectos como la sostenibilidad ecológica, la capacidad de carga, la estimación de los impactos y el ordenamiento territorial.

Los modelos de planificación turística con enfoque estratégico por su parte, introducen características como la definición de una filosofía, de escenarios futuros, de objetivos y metas de mediano plazo, de elección de prioridades, de análisis del entorno para la identificación de oportunidades y amenazas y la programación y participación de los actores sociales (Osorio García, 2006).

En los modelos de Clarke (2000) e Ivars (2003) se propone una forma de articular la planeación y la mercadotecnia turística en favor del desarrollo turístico. Sin embargo, estas difieren respecto a que el primer modelo incluye la participación de la población o de los actores sociales en dicho proceso, mientras que el segundo no.

La planificación territorial del turismo debe partir de la base de que existen dos niveles de planificación diferentes pero interconectados, a saber, un proceso colectivo: cuya responsabilidad recae sobre la administración y cuyo ámbito de actuación principal es el territorio, y otro individual: cuyos campos fundamentales se centran en lo económico-empresarial y en la creación de valor comercializable (Barrado Timón, 2004).

En resumen, el proceso de creación y ejecución de la planificación se hace más complejo al considerar en un mismo modelo los aspectos espaciales, ambientales y de mercado. La sostenibilidad se convierte en el principal aspecto de la planificación turística. No se trata de realizar una única planificación, sino un enfoque que permita vincular la perspectiva económica de localización de instalaciones, teniendo en cuenta los intereses individuales de empresas o grupos de estas, con la perspectiva coherente y racional del destino como un todo para el disfrute del turista.

\subsection{Decisiones de localización de las instalaciones en los destinos turísticos}

La literatura científica sobre localización de instalaciones ha sido abordada desde diferentes perspectivas, pero los autores asumen una definición conceptual que concibe a la localización de una instalación como el proceso de elegir un lugar geográfico entre varios para realizar las operaciones de una empresa, en este caso las vinculadas a la oferta restaurantera, (Carro y González, 2015). En este sentido el concepto se utiliza como una variable espacial, determinante en este caso en el proceso de toma de decisiones, y como parte de uno más abarcador que es el geomarketing (Latour y Le Floc'h, 2001; Chascos, 2003; Alcaide, et.al., 2012; Baviera, Buitrago, y Rodríguez, 2013; Avellaneda, 2014; Syagnik, 2019).

Por lo anterior es que los autores se refieren fundamentalmente a la oferta de localización de los restaurantes o más concisamente a la oferta restaurantera, y no a otros aspectos relacionados con la competencia y la demanda de los clientes, dado que a su juicio ha sido uno de los aspectos menos abordados en este tipo de estudio, criterio que comparten autores como Solsona Monzonís, y López Olivares, (2012); Carro Paz, y González Gómez; Li-Fei Chen y Chih-Tsung Tsai, (2015); He, Z., Han, et.al.; Jung, S., (2018) y Syagnik, (2019), entre otros.

Las decisiones de localización forman parte del proceso de formulación estratégica de un destino turístico. Una buena selección puede contribuir a la realización de los objetivos empresariales, mejorar la calidad de las decisiones de ubicación de una instalación, atraer más clientes e impactar sustancialmente la participación del mercado y obtener más rentabilidad, (Li-Fei Chen y Chih-Tsung Tsai, 2015), por ello es una de las consideraciones principales en un mercado emergente o en expansión. Por otro lado, una localización desacertada puede conllevar a un desempeño inadecuado de las operaciones (Molina Rodríguez, 2019; Rodríguez Sánchez, 2016).

La selección del emplazamiento en el que se van a desarrollar las operaciones de las instalaciones es una decisión de gran importancia. La significación de su impacto y las implicaciones que se derivan de ella justifican una atención y consideración adecuada por parte de la dirección. Esta importancia viene justificada por varias razones (Estay y Chávez, 2015): 
$\checkmark$ Las decisiones de localización no adecuadas de las instalaciones entrañan una inmovilización considerable de recursos financieros a largo plazo.

$\checkmark \quad$ Las malas decisiones de localización tomadas afectan a la capacidad competitiva de la instalación.

La localización forma parte de la estrategia de operaciones, especificando la forma en que estas pueden ayudar a implementar la estrategia corporativa de la empresa (Krajewski et al., 2002). El desarrollo de la estrategia de operaciones supone adoptar las decisiones que permiten alcanzar los objetivos establecidos. La gran variedad de decisiones a adoptar plantea la necesidad de efectuar una clasificación de los mismos, en este sentido se identifican cinco áreas de decisión relativas a las operaciones de acuerdo con un esquema funcional, estas son: proceso, capacidad, inventario, fuerza de trabajo y calidad (Metters y Pullman, 2014).

En concordancia con Gaithes y Frazier (2000), Chase et al. (2005), Schroeder (2006) y Diéguez Matellán (2008) se determinan como antecedentes de las decisiones de localización: el análisis del mercado y de la competencia; ya que son considerados como los primeros pasos a dar para el establecimiento de la estrategia de operaciones.

Otro antecedente importante según señalan Domínguez Machuca (1995) y López Morales y Ortega Ridaura (2016) es que la empresa debe identificar las opciones disponibles que garanticen valorar adecuadamente, sus amenazas, oportunidades, fortalezas y debilidades.

La decisión de localización a menudo depende del tipo de negocio. Para las decisiones de localización industrial, la estrategia usual es minimizar los costos, aunque la innovación y creatividad también pueden ser críticas. Para las organizaciones de venta al menudeo o servicios profesionales, la estrategia se enfoca en maximizar el ingreso. El objetivo de la estrategia de localización es maximizar el beneficio de la ubicación para la compañía (Estay y Chávez, 2015). En este sentido los autores sostienen que no es sólo ni fundamentalmente esto, sino la reducción de costos de búsqueda para los consumidores y la creación de condiciones para alcanzar altos niveles de calidad percibida por el cliente, en lugar de reducir los costos de producción, (Jung, 2018).

Cuando las alternativas potenciales se extienden a regiones o países diferentes, la decisión se habrá de sistematizar en niveles geográficos. En este sentido, suelen distinguirse dos o tres niveles (Domínguez Machuca, 1995; Krajewski et al., 2002), aunque la diferencia es más bien de forma que de contenido. Así, los que optan por tres niveles distinguen el nivel regional/internacional, el de la comunidad o ciudad y el del lugar concreto, mientras que los que distinguen dos, hablan de macroanálisis, o evaluación de países, regiones, comunidades o ciudades, y microanálisis, o evaluación de emplazamientos específicos.

Por otra parte, aunque se establecen varios procedimientos para el análisis de localización, no se aprecian diferencias significativas entre los mismos, predominando la tendencia al análisis por áreas o niveles geográficos. De manera general, el estudio de localización cuenta con dos etapas: la macro y la microlocalización. La primera ofrece la posibilidad de acotar el número de soluciones posibles, determinando la región óptima; la segunda, determina el emplazamiento definitivo del proyecto, partiendo de la región determinada en la primera etapa. En ambas etapas, se plantea la necesidad de analizar los factores asociados al proceso de localización.

En cuanto a los modelos matemáticos de localización (González Becerril, 2004), tanto el métrico metropolitano, como el métrico euclidiano y el método del centro de gravedad, analizan la posible ubicación de un nuevo negocio, partiendo de la población o clientela en el área geográfica en estudio. Por su parte Tzeng (2002) y Hsiao (2018), emplean el análisis de decisión multicriterio desde la perspectiva de los consumidores para situar un nuevo restaurante. Con este mismo objetivo, Yang (2017) aplica un modelo de regresión binomial negativo y Wang y Yan (2017) realizan un análisis clúster por regiones, de la posible distribución de restaurantes. Así, los principales procedimientos se basan en modelaciones matemáticas que conjugan las variables de interés en el espacio geográfico en cuestión.

Sin embargo, no resultan aplicables para el análisis de servicios ya establecidos y en el caso turístico en particular, resulta complejo definir la población o clientela real, toda vez que los clientes circulan libremente por el destino, sin tener en cuenta los visitantes que también se consideran consumidores potenciales.

No obstante, resulta útil el empleo de Sistemas de Información Geográfica (Neteler y Misatova, 2013), los que permiten consultar de manera interactiva información geográfica digital (latitud, longitud, altitud), facilitando la combinación e integración de múltiples cartografías (Taylor, 2013), manejadas como capas superpuestas de datos que se observan simultáneamente (Longley, 2015) y como características de un mismo espacio, para la generación de información aplicable a proyectos o cuestiones específicas (Jiménez Moya et al., 2016). 
Si bien la problemática de localización de nuevos restaurantes en destinos turísticos ha sido abordada en la literatura, existen escasos referentes de estudios que aborden el análisis de la distribución de la oferta gastronómica ya establecida. Fundamentada su necesidad, en el crecimiento progresivo de los destinos turísticos en la medida que evolucionan, lo que consecuentemente implica una reconfiguración de los servicios y su oferta.

\section{METODOLOGÍA}

La investigación se propuso como objetivo el análisis de la localización actual de los servicios de restaurante en el destino turístico Varadero, Cuba; basado en las variables oferta y distribución geográfica, y su incidencia en la percepción de variedad por parte de los turistas. Teniendo en cuenta los factores relacionados con la satisfacción de los clientes (Soulard et al., 2018) y su aporte a la diversidad del destino (Torres Oñate et al., 2018).

El procedimiento seguido se muestra en la figura 3. Su despliegue se sustenta en un estudio de campo, el empleo de SIG y herramientas de análisis estadístico para la identificación de "puntos calientes" en la distribución de la oferta.

Figura 3 - Procedimiento para el análisis de la distribución

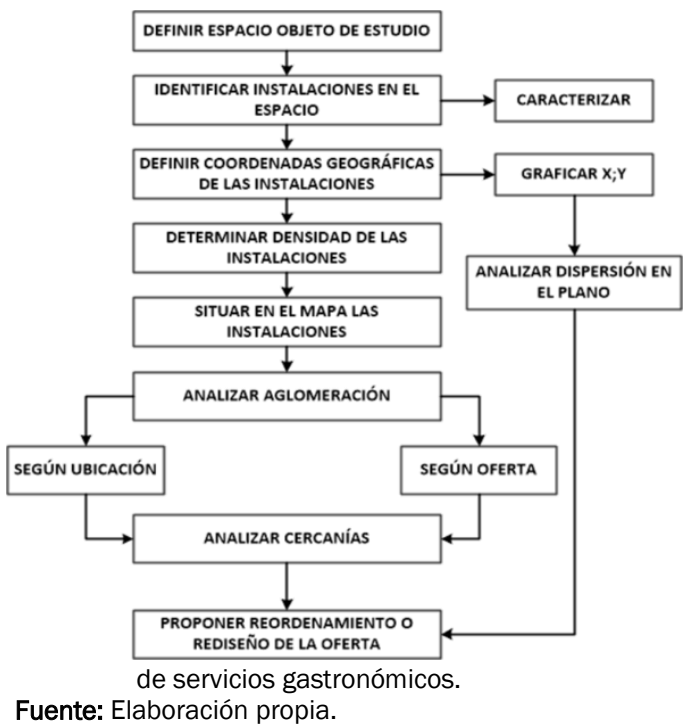

\subsection{Método de análisis}

De acuerdo con Ávila Bercial y Barrado Timón (2005) y Medina Argueta y Rosado Varela (2014) en cualquier estudio de localización resulta fundamental acotar el área a la cual se circunscribe el análisis. La definición del espacio geográfico implica su delimitación superficial, para lo cual pueden tenerse en cuenta diversas variables como: delimitación previa del área, distribuciones geográficas preestablecidas, variables sociodemográficas, variables administrativas, intereses económicos y/o comerciales, entre otras, (González Becerril, 2004; Saarinen, 2017).

Varadero, se ubica en el punto más septentrional de la isla de Cuba, con $22 \mathrm{~km}$ de playa se encuentra al norte de la provincia de Matanzas y constituye la península de Hicacos. Cuenta con una zona denominada Varadero histórico (desde su entrada hasta la calle 60) donde se ubica la mayor parte de la oferta gastronómica y desde este punto hasta el final, la zona de desarrollo de la planta hotelera de mayor envergadura. La zona histórica fue la seleccionada como área de estudio dado el alto consumo por los clientes que transitan con mayor frecuencia por el polo. Asimismo, las quejas de los clientes relacionadas con la poca variedad de servicios gastronómicos, se refieren a los restaurantes situados en esta área. El espacio en cuestión comprendió desde el restaurante Kiki`s Club situado en Calle 5 y Avenida Kawama, hasta el restaurante La Barbacoa localizado en Calle 64 y Avenida Primera (Figura 4). 


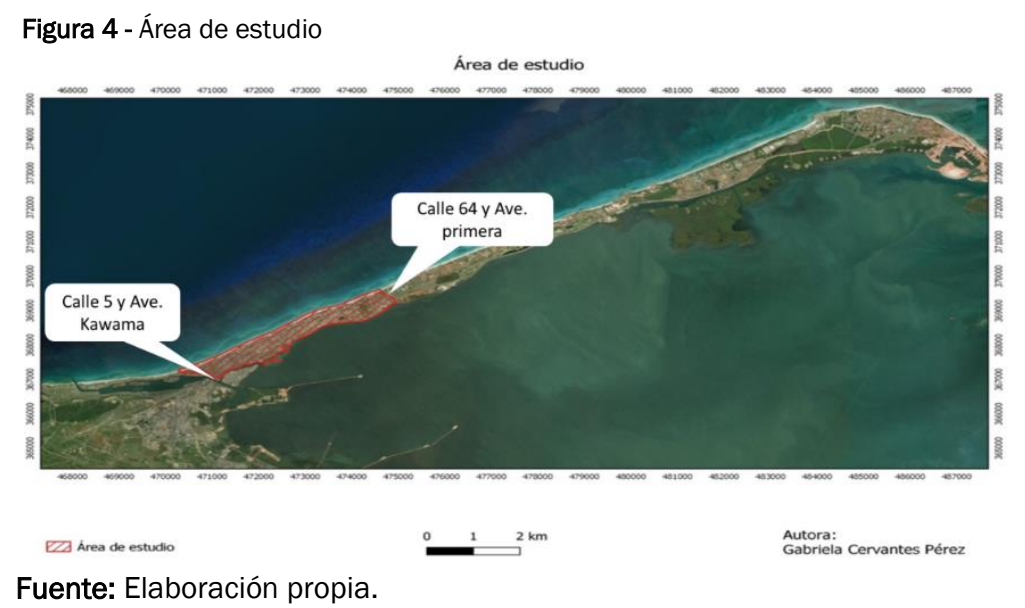

El estudio abarcó las 43 instalaciones situadas en el área, independientemente de su forma de gestión. Para recabar toda la información posible, a fin de contar con una caracterización de cada entidad que propicie los análisis posteriores se entrevistaron las administraciones de cada entidad y tabularon ordenadamente los datos: nombre del restaurante, dirección, clientes promedio por día y tipo de oferta (internacional, criolla o especializada). Asimismo, se registraron las coordenadas cartográficas (latitud y longitud) de cada restaurante (tabla 1).

Tabla 1 - Registro de datos de las entidades en estudio

\begin{tabular}{|c|c|c|c|c|}
\hline Nombre & Dirección & Clientes/día & Tipo de oferta & \\
\hline
\end{tabular}

Fuente: Elaboración propia.

La determinación de las coordenadas de cada entidad propició su ubicación en el mapa y el trabajo con los SIG, además constituyeron la referencia para definir la distancia entre los restaurantes. Las coordenadas cartográficas se registraron mediante la aplicación móvil MapsMe, la cual se basa en el sistema GPS con una aproximación de cinco metros (figura 5). Estas se interpretaron como pares cartesianos (x;y), de forma tal que su representación gráfica permitió analizar gradientes de distribución de los restaurantes de acuerdo a las variables de interés.

La determinación de la densidad de restaurantes ofrece una medida de su concentración en el área objeto de estudio. Para su cálculo se definió la superficie en $\mathrm{Km}^{2}$ que cubre el área delimitada. La determinación del área de superficie se realizó mediante el software QGis, que ofrece además un entorno de trabajo sencillo y amigable (Jiménez Moya et al., 2016).

Para el cálculo de la densidad de restaurantes se empleó (1)

$$
D s g=\frac{\sum r e s t}{S}
$$

\section{Dónde:}

Dsgai: densidad

Srest: sumatoria de los restaurantes localizados dentro del área objeto de estudio

S: área objeto de estudio en $\mathrm{Km}^{2}$ 


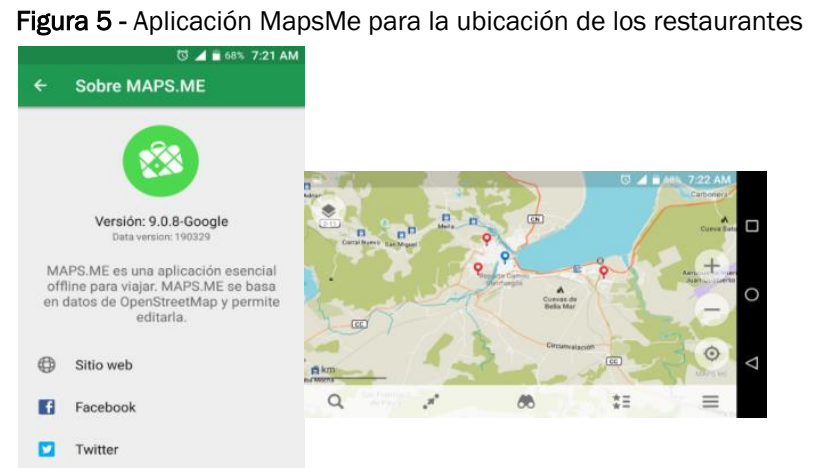

Fuente: Tomado de la aplicación.

De esta forma, se obtuvo la cantidad de restaurantes existentes por $\mathrm{Km}^{2}$ en el área estudiada. Aunque la literatura no ofrece un valor óptimo de este indicador, su determinación resulta de interés en la investigación puesto que ofrece una panorámica de la distribución existente.

Con la información recopilada en la tabla 1 se ubicaron en el mapa con el empleo del software QGis, realizándose un análisis global y por tipo de oferta, de la distribución en el área objeto de estudio

Para el análisis de la aglomeración, se emplearon dos variables. La primera, ubicación geográfica de acuerdo al lugar donde se encuentran, donde se tuvieron en cuenta las distancias mínimas entre establecimientos. La otra variable a analizada fue la oferta. De acuerdo al tipo de oferta que brindan es posible determinar si existe aglomeración, en función de la distancia mínima entre restaurantes con la misma oferta de alimentos; lo que incide directamente en la percepción de variedad (Torres Oñate et al., 2018). Los restaurantes fueron agrupados en tres grupos: Criollos, Especializados e Internacionales.

Para el tratamiento estadístico de los datos se seleccionó el Análisis de Conglomerados por el método de los Centroides, empleando como métrica de distancia para la determinación de similitudes la de Bloque Habitacional, mediante el software Statgraphics. Con el objetivo de crear conglomerados, es importante tener una medida de “cercanía" o "similaridad" tal que los objetos parecidos puedan ser juntados, en este caso, la oferta.

Asimismo, a partir de las opciones gráficas se seleccionó del grafo 2D, donde de acuerdo a las variables utilizadas (coordenadas cartográficas) se muestran los conglomerados en coincidencia con su localización.

Para contrastar los conglomerados resultantes, se realizó un mapa de calor mediante el QGis, lo que permitió identificar la aglomeración de restaurantes en algunas zonas, así como la presencia de centroides. Para la elaboración de estos centroides, se tomó como referencia un radio de 100 metros. Esta medida responde a las características del área en estudio y la concentración de servicios.

El estudio de la distribución en el plano se concluyó con la determinación de las distancias geodésicas mínimas entre restaurantes, considerando el trazado urbano y con el empleo de la matriz que se muestra en la tabla 2.

$\underline{\text { Tabla } 2 \text { - Arreglo matricial para determinar las distancias entre restaurantes }}$

\begin{tabular}{lll} 
& R1 & R2 \\
\hline R1 & & \\
Rn & & \\
\hline Fuente: Elaboracon & & \\
\hline
\end{tabular}

Fuente: Elaboración propia.

Finalmente, sobre la base del análisis de los resultados anteriores, se propusieron acciones para mejorar la distribución actual de los servicios gastronómicos. Las sugerencias no se encaminan solo al cambio de localización, teniendo en cuenta el costo de inversión, sino también a la reformulación de la oferta, lo cual puede resultar mucho más factible desde el punto de vista económico. Asimismo, las propuestas pueden orientarse a tener en cuenta espacios vacíos apoyando la toma de decisiones respecto a lugar y tipo de establecimiento, en el caso de apertura de nuevas instalaciones.

\section{ANÁLISIS Y DISCUSIÓN DE LOS RESULTADOS}

El trabajo de campo desarrollado en el área en estudio, a partir de la identificación de los 43 restaurantes, resumió en la tabla 3 los datos de interés para el análisis de la localización. 
Tabla 3 - Servicios gastronómicos en el área

(Cont...)

\begin{tabular}{|c|c|c|c|c|c|}
\hline \multirow{2}{*}{\multicolumn{2}{|c|}{ Nombre }} & \multirow[t]{2}{*}{ Dirección } & \multirow[t]{2}{*}{ Tipo de oferta } & \multicolumn{2}{|l|}{ Coordenadas } \\
\hline & & & & Latitud & Longitud \\
\hline R1 & Kiki s Club & Calle 5 Ave. Kawama & Internacional & 23.134499 & -81.285607 \\
\hline R2 & Sangría & Calle 7 Ave. Kawama esq. & Internacional & 23.134504 & -81.28451 \\
\hline R3 & Sakura & Calle 9 e/camino del mar y Ave. Kawama & Especializado & 23.136011 & -81.284767 \\
\hline R4 & Castell Nuovo & Calle 11 Ave. Primera esq. & Internacional & 23.135446 & -81.282235 \\
\hline R5 & Casa del Chef & Calle 12 Ave. Primera esq. & Internacional & 23.136274 & -81.28186 \\
\hline R6 & Comida rápida & Calle 13 Ave. Primera esq. & Especializado & 23.137051 & -81.281814 \\
\hline R7 & Bellamar & Entre calle 15 y 18 Ave. Primera & Internacional & 23.13928 & -81.280102 \\
\hline R8 & Pequeño Suarez & Calle 18 e/ Ave. 3era y Ave. 2da & Internacional & 23.13859 & -81.278308 \\
\hline & El Criollo & Calle 18 esq. Ave. 1ra & Criollo & 23.139752 & -81.2791 \\
\hline R10 & Lai Lai & Calle 18 y playa & Especializado & 23.140403 & -81.279084 \\
\hline R11 & Vaca Rosada & Calle $21, \# 102 \% 1$ era y 2 da avenida & Internacional & 23.140302 & -81.27656 \\
\hline R12 & Steak House & Calle 25,1era Ave & Especializado & 23.14247 & -81.274304 \\
\hline R13 & Casa de la Miel & Calle 26 1era Ave & Especializado & 23.142623 & -81.274052 \\
\hline R14 & Terracita Café & Calle $28 / 29$ 1era Ave & Especializado & 23.143274 & -81.271801 \\
\hline R15 & Don Alex & Calle 31, entre 1ra y 3ra Ave, N0.106 & Especializado & 23.143718 & -81.269817 \\
\hline R16 & Salsa Suárez & Calle 31 e/ Ave. Primera y Tercera & Internacional & 23.143992 & -81.269701 \\
\hline R17 & Vernissage & Esquina calle 36,1 ra Ave & Internacional & 23.146069 & -81.266855 \\
\hline R18 & Esquina Cuba & Esquina calle 36,1 ra Ave & Criollo & 23.146231 & -81.266555 \\
\hline R19 & Melaito & Entre calle 37 y 38 1ra Ave & Criollo & 23.146877 & -81.266096 \\
\hline R20 & Vicaria & Calle 38 1era Ave & Criollo & 23.147173 & -81.265766 \\
\hline R21 & Nonna Tina & Calle 38 No5, entre 1 ra Ave y Playa & Especializado & 23.147368 & -81.265619 \\
\hline R22 & La Bodeguita del Medio & Esquina 40 entre 1era Ave y playa & Internacional & 23.148305 & -81.264377 \\
\hline R23 & El Caney & En 1era avenida esquina 40 & Internacional & 23.147965 & -81.264098 \\
\hline R24 & Sabor Cubano & Calle 40 1era Ave & criollo & 23.147953 & -81.26376 \\
\hline R25 & Doña Nelly & Calle 43 y 1 era Ave & Especializado & 23.149031 & -81.26232 \\
\hline R26 & En Familia & Entre calle 44 y 47,1 era Ave & Especializado & 23.150172 & -81.261035 \\
\hline R27 & Casona del Arte & Calle 47, entre 1ra. Ave. y Ave. Playa, \# 06 & Internacional & 23.150754 & -81.25908 \\
\hline R28 & El Rápido 47 & Calle 47, entre 1ra. Ave. Y Ave. Playa & Especializado & 23.150676 & -81.258573 \\
\hline R29 & Bodegón del Gordo & Calle 49 entre 1era y 2da Ave \#106 & Internacional & 23.150396 & -81.257285 \\
\hline R30 & El Itsmo & Entre calle 52 y 53,1 era Ave & Internacional & 23.151748 & -81.254963 \\
\hline R31 & Los Tres Cerditos & Calle 54 entre quinta y sexta Ave. & Internacional & 23.151748 & -81.254963 \\
\hline R32 & El Palacio de la Pizza & Calle 54 y autopista & Especializado & 23.149588 & -81.251969 \\
\hline R33 & El Quitrín & Calle 55 primera Ave & Criollo & 23.152747 & -81.252785 \\
\hline R34 & La Campana & Calle 56 Parque Josone & Criollo & 23.15141 & -81.251143 \\
\hline R35 & El Retiro & Calle 56 Parque Josone & Internacional & 23.152207 & -81.251599 \\
\hline R36 & El Dante & Calle 56 Parque Josone & Especializado & 23.152103 & -81.251304 \\
\hline R37 & El Rancho & Entre calle 57 y 58 Ave 1 ra & Internacional & 23.153568 & -81.25125 \\
\hline R38 & Waco s Club & Entre 58 y 59 Ave 3era & Internacional & 23.151632 & -81.249389 \\
\hline R39 & Restaurante de Cuatro Palmas & Calle 60 entre 1era y 2 da Ave & Internacional & 23.153637 & -81.24961 \\
\hline R40 & Varadero 60 & Calle 61 esq. Ave. 3ra & Internacional & 23.15214 & -81.248236 \\
\hline R41 & Casa del Chocolate & Calle 61 primera Ave & Internacional & 23.154528 & -81.248834 \\
\hline R42 & Fondue & Entre calle 62 y 63 1era Ave & Especializado & 23.154646 & -81.248337 \\
\hline R43 & Barbacoa & Calle 64 e/Ave. 1ra y playa & Internacional & 23.1556 & -81.247391 \\
\hline
\end{tabular}

Fuente: Elaboración propia.

De los 43 restaurantes, según el tipo de administración 30 son estatales, 10 corresponden al sector privado y 3 son cooperativas. Según el tipo de oferta se identifican: 7 Criollos, 14 Especializados y 22 Internacionales (figura 6). Teniendo en cuenta la intención de comunicar una imagen de Auténtica Cuba, resulta contrastante la poca existencia de restaurantes dedicados a la cocina criolla.

Figura 6 - Composición de la oferta

COMPOSICIÓN DE LA OFERTA

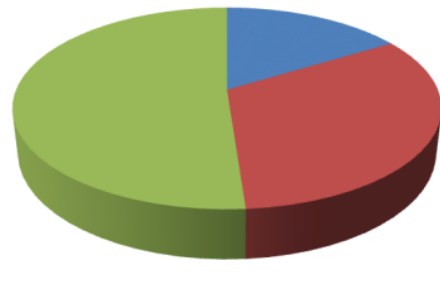

ente: Elaboración propia. 
Los restaurantes se distribuyen de izquierda a derecha en la diagonal, partiendo del borde inferior izquierdo. Si bien se percibe un comportamiento lineal de su disposición en el plano, en el borde superior derecho los restaurantes se dispersan ligeramente. Lo anterior supone que las instalaciones cubren un área mayor en esta zona (Figura 7).

Figura 7 - Distribución de los servicios de restaurantes en el plano, de acuerdo a las coordenadas cartesianas

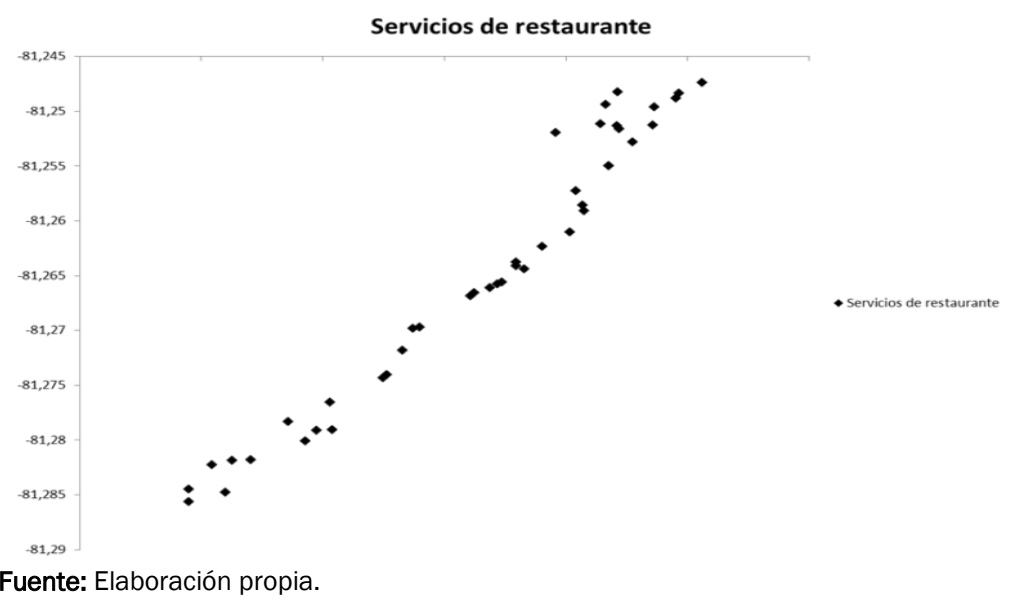

En la figura 8, se dividió el gráfico en cuadrantes a partir de la media de los valores x; y.

Figura 8 - División de la distribución de los restaurantes a partir de la media de los valores x; y

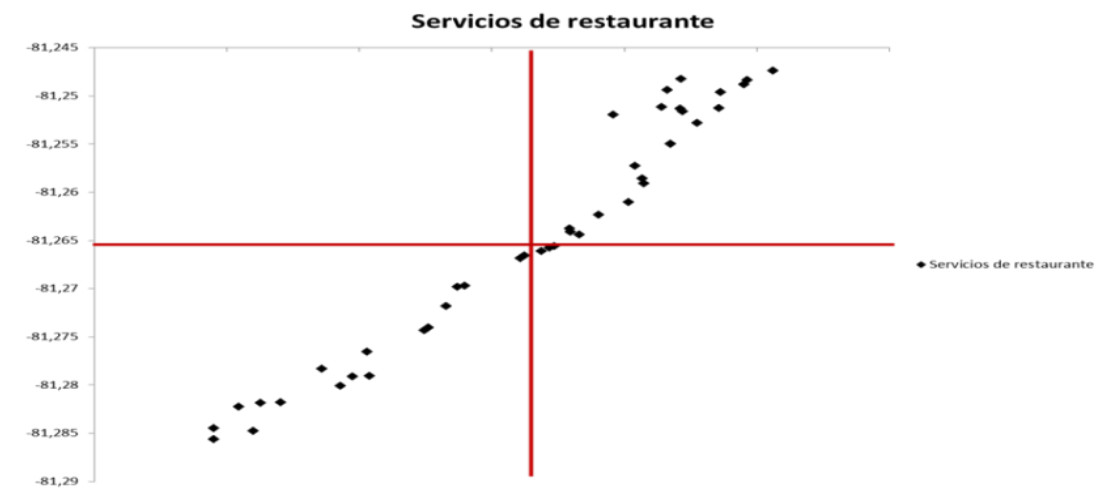

Fuente: Elaboración propia.

Este análisis confirma el planteamiento derivado de la figura 7. En el borde superior derecho se sitúan 21 restaurantes y en el borde inferior izquierdo 18, denotando leve desbalance hacia el extremo derecho del plano. En los cuadrantes, izquierdo-superior y derecho-inferior, no se localizan instalaciones, pudiendo estar condicionado este comportamiento a características topográficas.

Al ubicar los valores relativos al tipo de oferta, los restaurantes Criollos (7) se concentran en la zona central (4) y poseen una mínima representación en los extremos izquierdo-inferior (1) y derecho-superior (2) como se muestra en la figura 9.

Figura 9 - Distribución de los restaurantes según tipo de oferta (criolla)

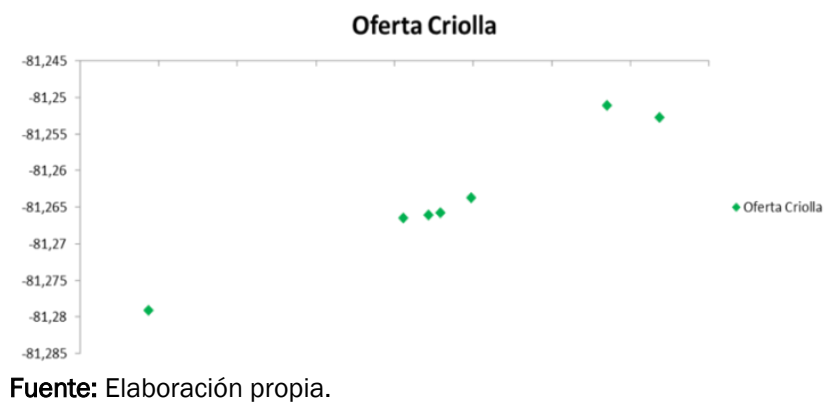


Este comportamiento indica que es preciso ampliar la oferta de cocina cubana en el área objeto de estudio, toda vez que basa su campaña promocional en el slogan “Auténtica Cuba”. Resulta contrastante por tanto, la escasa representación de ofertas gastronómicas dedicadas a nuestras raíces culinarias, así como su desbalance en la distribución actual.

Respecto al tipo de oferta Especializada (14), resaltan los restaurantes dedicados a la cocina asiática, platos a base de pollo y particularidades gastronómicas como el queso, la miel y cortes de carne vacuna. En cuanto a su distribución (figura 10) estos se encuentran más dispersos en el plano con lo cual pueden ser mejor percibidos por los clientes. En la zona central se agrupan cuatro de estos servicios, relativamente cercanos unos a otros, lo que puede afectar su comercialización toda vez que como productos sustitutivos compiten por los mismos clientes, además de comprometer la percepción de variedad de la oferta, uno de los aspectos que sustenta la presente investigación.

Figura 10 - Distribución de los restaurantes según tipo de oferta (especializado)

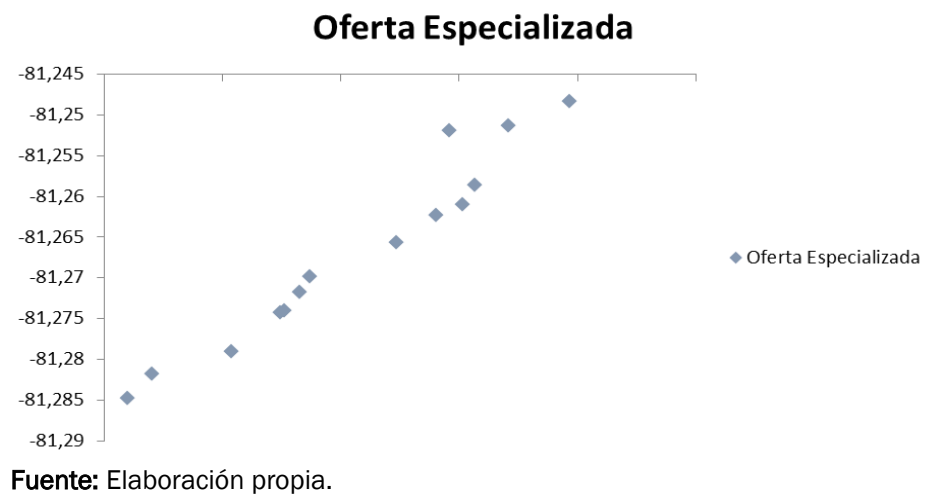

En cuanto a la oferta Internacional (21), esta resulta significativamente superior. Si bien muchos de estos servicios incluyen en sus cartas platos de la cocina cubana, se venden como restaurantes de cocina criolla e internacional. Esta ambigüedad causa confusión en los clientes, a la vez que distorsiona la autenticidad de los platos de nuestra cocina. No obstante este comportamiento de mezcla de cocinas resulta habitual en el entorno gastronómico cubano ${ }^{1}$.

Respecto a la distribución de la oferta Internacional (figura 11) existe poca presencia en la zona central del plano y muestran una mayor dispersión en el extremo derecho-superior.

Figura 11 - Distribución de los restaurantes según tipo de oferta (internacional)

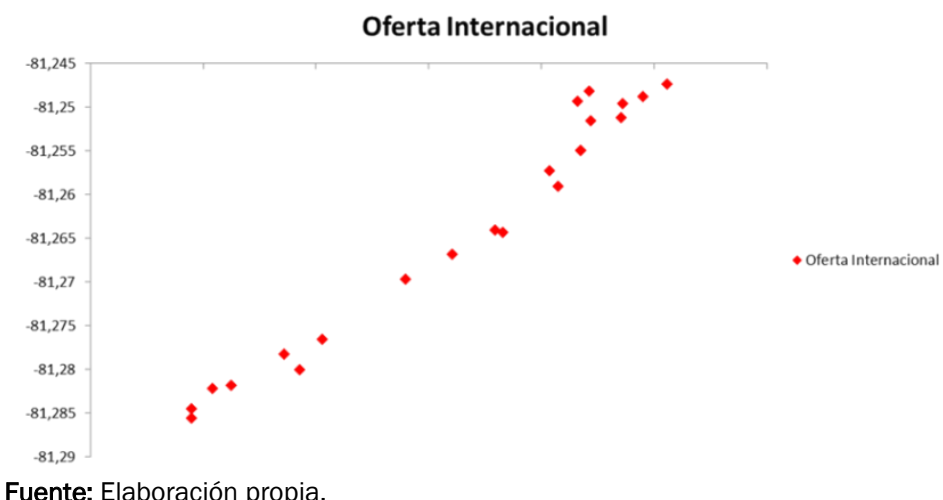

\section{Densidad de los servicios gastronómicos}

La zona abarca $4.2 \mathrm{Km}^{2}$ aproximadamente. De acuerdo con (1) se localizan 10 restaurantes por $\mathrm{Km}^{2}$ en el área objeto de estudio.

\footnotetext{
${ }^{1}$ De acuerdo con el sitio www.blog.cubapaladar.org. Pionero de la crítica culinaria en Cuba
} 


$$
\begin{gathered}
D s g=\frac{\sum \text { rest }}{S} \\
D s g=\frac{43 \text { retaurantes }}{4.2 \mathrm{~km}^{2}} \\
D s g=10.23 \approx 10 \text { retaurantes } / \mathrm{km}^{2}
\end{gathered}
$$

Si bien es una medida general, pudiendo haber mayor o menor concentración en áreas determinadas, el cliente que transita por la zona objeto de estudio, tiene la probabilidad de encontrarse con 10 restaurantes por Km². Visto así, se infiere cierta concentración de restaurantes en el destino, lo que se acrecienta dada la desigual distribución de la oferta actual. Solo existen 7 restaurantes de cocina Criolla, contra 21 de cocina Internacional y 14 de cocina Especializada, por cada un restaurante de comida cubana existen 2 de comida Especializada y 3 de comida Internacional. Lo que corrobora el desbalance de la variedad de la oferta.

Tomando como referencia el tipo de oferta, donde 7 restaurantes son de comida Criolla (DsC), 14 son Especializados (DsE) y 22 brindan comida Internacional (Dsl), la densidad quedó de la siguiente manera:

$$
\begin{gathered}
\text { DsC }=\frac{\sum \text { rest }}{S} \\
D s C=\frac{7 \text { restaurantes }}{4.2 \mathrm{Km}^{2}} \\
D s C=1,6 \approx 2 \text { restaurantes } / \mathrm{Km}^{2} \\
\text { DsE }=\frac{\sum \text { rest }}{S} \\
D s E=\frac{14 \text { restaurantes }}{4.2 \mathrm{Km}^{2}} \\
D s E=3.33 \text { restaurantes } / \mathrm{Km}^{2} \\
\text { DsI }=\frac{\sum \text { rest }}{S} \\
D s I=\frac{22 \text { restaurantes }}{4.2 \mathrm{Km}^{2}} \\
D s I=5.23 \text { restaurantes } / \mathrm{Km}^{2}
\end{gathered}
$$

Profundizando en este sentido, dirigido a cada tipo de oferta en particular la densidad de restaurantes Criollos por $\mathrm{Km}^{2}$ es de 2 restaurantes. En el caso de restaurantes Especializados es de 3 y para la cocina Internacional de 5 restaurantes.

\section{Localización en el mapa de los restaurantes}

En la figura 12, se observa que la península de Varadero se orienta de oeste a este, con un gradiente hacia el noreste. El área en cuestión es alargada en la diagonal de izquierda a derecha (oeste-este) y estrecha a todo lo ancho. En promedio su extensión a lo largo del gradiente es de aproximadamente 5,2 km y de ancho apenas supera los $0,7 \mathrm{~km}$ como media.

Figura 12 - Distribución de los restaurantes en el mapa según el tipo de oferta

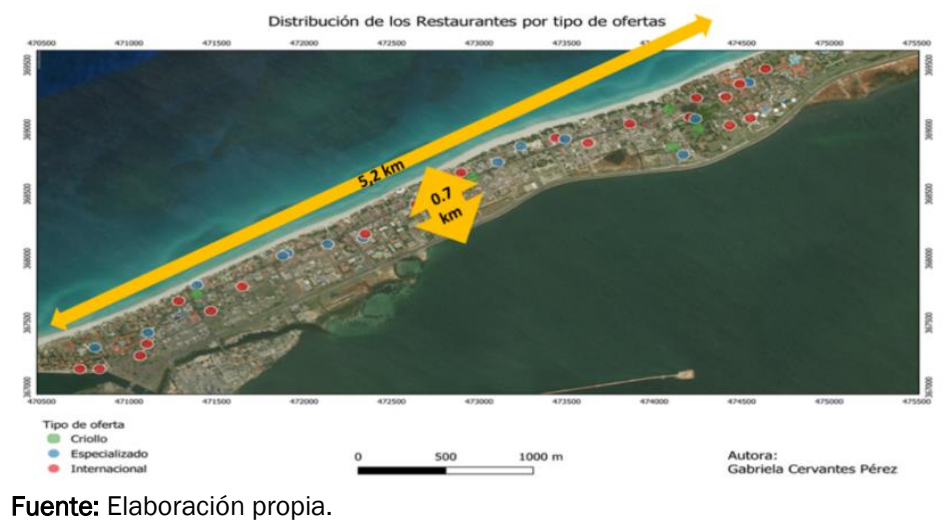

Además, se confirman los resultados de la ubicación de las coordenadas cartesianas en el plano. La distribución responde a las propias características topográficas del área seleccionada. Asimismo, no se evidencian barreras geográficas (a excepción de mar) que condicionen la localización de las entidades. 
La oferta criolla en este caso no solo es minoría, además su distribución mostró representaciones al inicio del área, tres relativamente cercanos hacia la zona central y 3 al final (figura 13).

Figura 13 - Distribución de los restaurantes de comida criolla

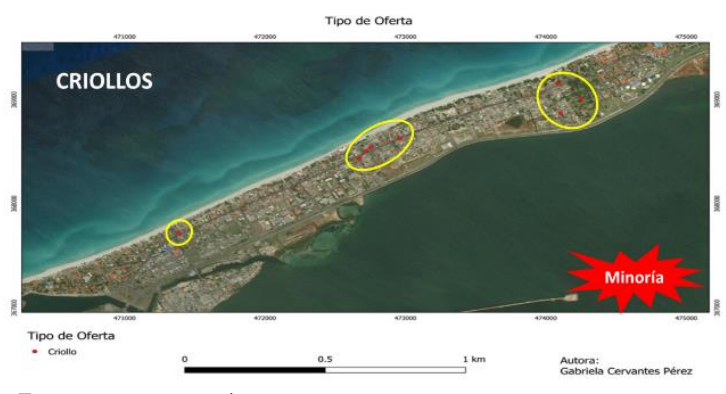

Fuente: Elaboración propia.

La oferta especializada (figura 14) evidenció una distribución más homogénea localizándose a lo largo de la zona en estudio. Asimismo, no se evidenciaron concentraciones de este tipo de restaurantes a priori.

Figura 14 - Distribución de los restaurantes de cocina especializada

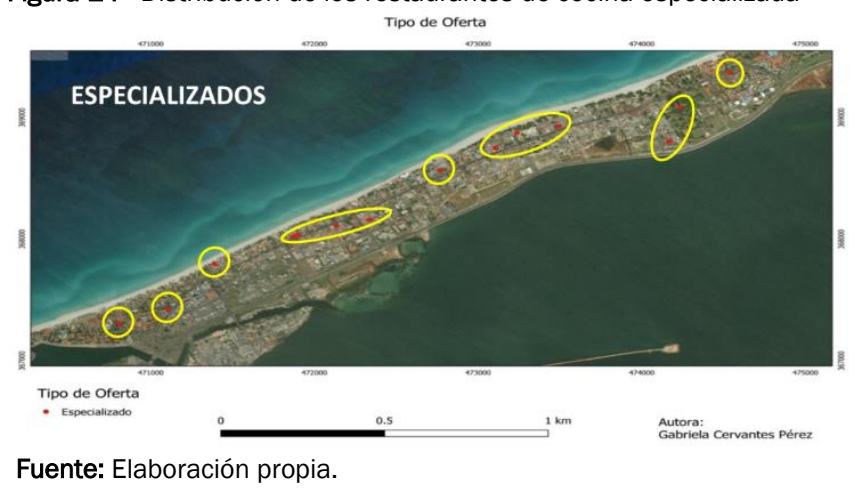

La oferta internacional a pesar de ser mayoritaria, no se encuentra concentrada. Aunque se observó una prevalencia en la zona superior-derecha del área objeto de estudio (Figura 15).

Figura 15 - Distribución de los restaurantes de comida internacional

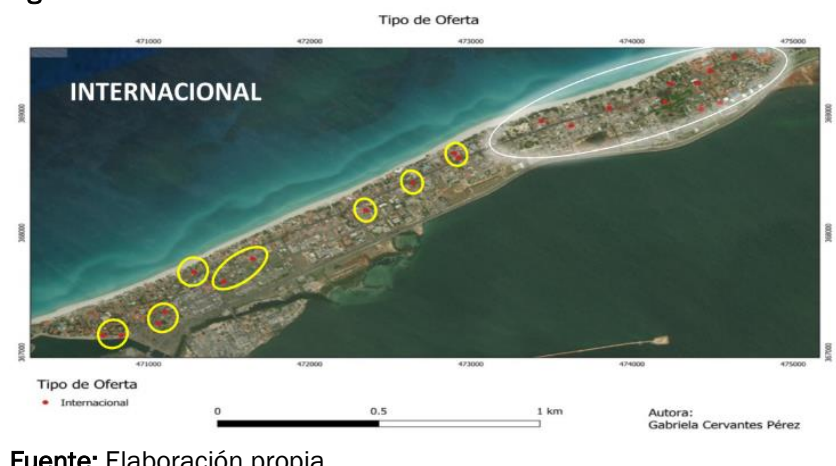

La distribución de los restaurantes según el tipo de oferta (figuras 13, 14, 15) evidenció la carencia de restaurantes de comida Criolla así como, su deficiente distribución en el plano, su dispersión no se corresponde con el valor de la densidad correspondiente (2 restaurantes $/ \mathrm{km}^{2}$ ) respecto al total de restaurantes existentes. Se evidenciaron además áreas vacías, con una distancia significativa entre las ofertas.

Contrasta el elevado número de restaurantes Internacionales ante la oferta Criolla, si se tiene en cuenta la campaña promocional de ventas del destino bajo el slogan "Auténtica Cuba". Este comportamiento compromete la percepción de variedad de la oferta gastronómica en el destino y la proyección de la imagen deseada, en consonancia con Batista Sánchez et al. (2017). 


\section{Análisis de la aglomeración de los restaurantes}

El Análisis de Conglomerados, utilizando el método de centroide mediante un diagrama de dispersión 2D, mostró la existencia de 5 conglomerados (tabla 4).

Tabla 4 - Conglomerados existentes en el área objeto de estudio

\begin{tabular}{lll}
\hline Conglomerado & Miembros & Porcentaje \\
\hline 1 & 6 & 13,95 \\
2 & 5 & 11,63 \\
3 & 5 & 11,63 \\
4 & 9 & 20,93 \\
5 & 18 & 41,86 \\
\hline Fuente: Elaboración propia. & &
\end{tabular}

En la figura 16 se muestran los 5 conglomerados a partir de las 43 observaciones. Se aprecia una mayor concentración de restaurantes en el último conglomerado (41,6\%), lo que confirma estadísticamente el desbalance existente en su distribución general.

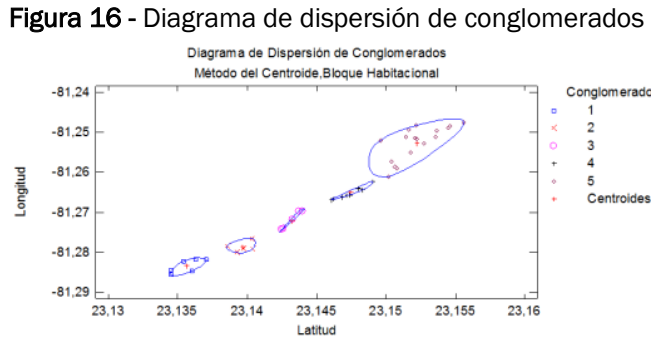

Fuente: Elaboración propia.

Este análisis por tipo de oferta (figura 17), evidenció 3 conglomerados para los restaurantes Especializados e Internacionales, en ambos casos destaca un conglomerado formado por el $50 \%$ de la oferta, que además coinciden en la zona de aglomeración. Este comportamiento, reafirma la deficiente dispersión de los restaurantes, en cuanto a ubicación geográfica y tipo de oferta.

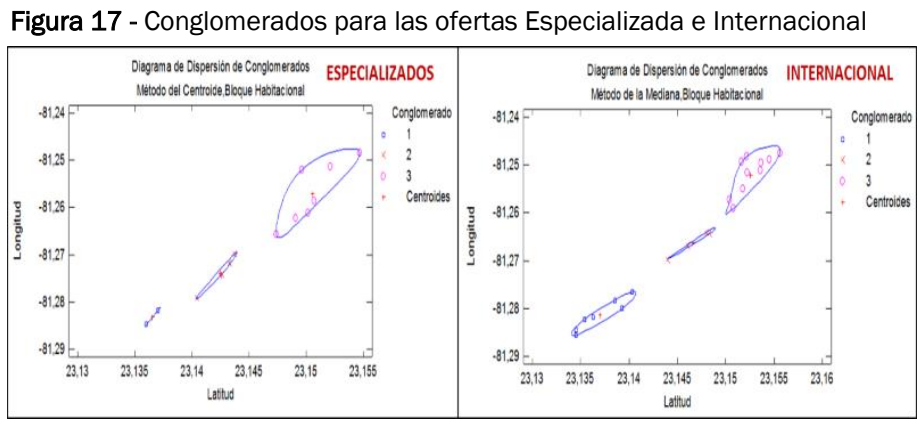

Fuente: Elaboración propia.

No obstante, teniendo en cuenta el desplazamiento de los clientes, se definió una distancia mínima entre restaurantes de 100 metros, para el estudio de la proximidad entre instalaciones. A partir del SIG se ubicaron los 43 restaurantes, según sus coordenadas cartográficas y mediante un análisis buffer (mapa de calor) se identificaron las zonas con mayor aglomeración para la distancia mínima prefijada (figura 18). 
Figura 18 - Análisis de proximidad para 100 metros

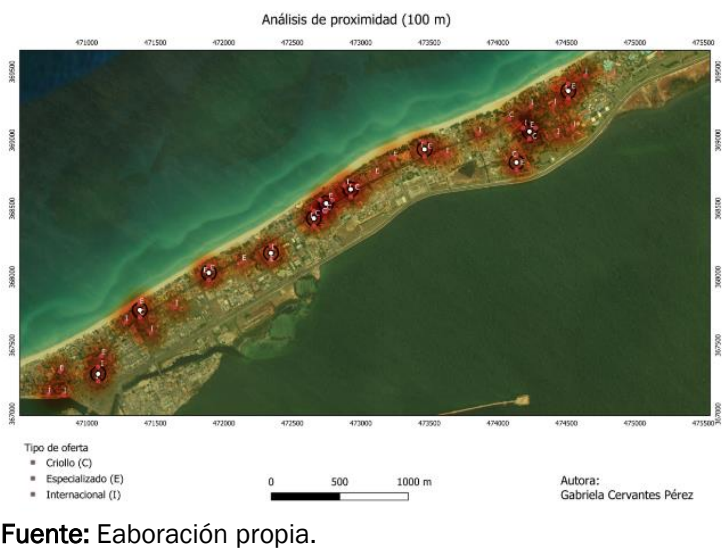

Con el mapa de calor para un radio de 100 metros se identificaron 11 centroides, lo que evidencia 11 puntos donde la distancia entre restaurantes es menor o igual. Se apreció mayor concentración de los restaurantes en la zona comprendida entre las calles 36 a la 38 (zona central), con la presencia de 8 restaurantes. La otra zona con aglomeración de restaurantes, se ubica entre las calles 54 a la 64 (zona superior-derecha), para un total de 14 (tabla 5).

\begin{tabular}{llll}
\multicolumn{2}{l}{ Tabla 5 - Composición de los centroides a menos de $100 \mathrm{~m}$} & \\
\hline Centroides $\mathbf{( 1 0 0} \mathbf{~ m})$ & Cantidad de restaurantes & Zona & Oferta \\
\hline 1 & 2 & Inf-izq & Similar \\
2 & 2 & Inf-iz & Diferente \\
3 & 2 & Inf-izq & Similar \\
4 & 2 & Inf-izq & Diferente \\
5 & 2 & Central & Diferente \\
6 & 3 & Central & Diferente* \\
7 & 3 & Central & Diferente* \\
8 & 2 & Supr-der & Diferente \\
9 & 2 & Sup-der & Diferente \\
10 & 3 & Sup-der & Diferente \\
11 & 2 & Sup-der & Diferente \\
\hline
\end{tabular}

Fuente: Elaboración propia.

Estos resultados evidenciaron la presencia de aglomeraciones de los restaurantes en diferentes zonas del plano en sentido general, lo cual atenta contra la variedad de la oferta en términos de cantidad de instalaciones. Destaca además que, en los centroides 1 y 3 la oferta es similar y en los centroides 6 y 7 (*) dos de los restaurantes que los componen ofertan comidas similares.

Respecto al tipo de oferta en el caso de los restaurantes Criollo, se evidenció un centroide en un radio de 100 metros. Igualmente para la oferta Especializada aunque, se especializan en comidas diferentes; el primero basa sus platos en cortes de carne de res y el segundo, en la elaboración de platos a base de pollo, por lo que no atenta contra la poca variedad a pesar de su cercanía. Sin embargo, para los restaurantes Internacionales, oferta predominante en el destino, se identificaron 3 centroides. El primero ubicado en la calle 12, con el restaurante Castell Nuovo y Casa del Cheff. El segundo en la calle 40 con La Bodeguita del Medio y El Caney. Y un tercero conformado por dos restaurantes evidenciándose que en esta zona se localizan otros 5 restaurantes Internacionales, que si bien distan entre ellos más de 100 metros, se encuentran relativamente cercanos (figura 19). 
Figura 19 - Análisis de proximidad, restaurantes de comida Internacional

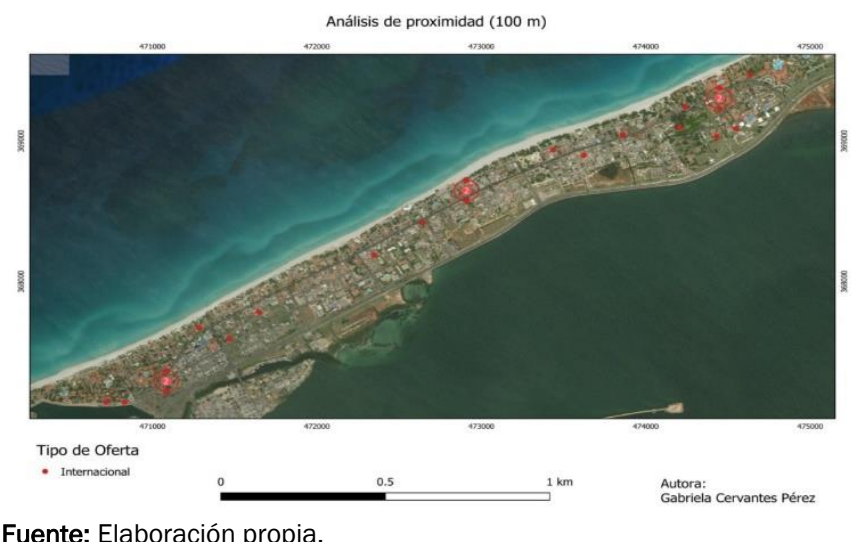

\section{Análisis de cercanías}

Si bien el análisis de proximidad para un radio de 100 metros ofrece una visión de la cercanía de los restaurantes, surgió la inquietud de valorar la distancia mínima entre las instalaciones, teniendo en cuenta el trazado urbano. De esta forma es posible obtener una panorámica general de la distribución de los restaurantes en el plano en términos de cercanía.

Mediante GPS se tabuló la distancia de cada restaurante respecto al resto para identificar luego la distancia mínima de un restaurante respecto a otro (tabla 6).

\begin{tabular}{llll} 
Tabla 6 - Distancias mínimas & & & \\
\hline Restaurantes & Dist. mínima $(\mathrm{m})$ & Restaurantes & Dist. mínima $(\mathrm{m})$ \\
\hline Kiki s Club & 130 & El Caney & 48 \\
Sangría & 240 & Sabor Cubano & 48 \\
Sakura & 240 & Doña Nelly & 250 \\
Castell Nuovo & 160 & En Familia & 280 \\
Casa del Chef & 130 & Casona del Arte & 140 \\
Comida rápida & 130 & El Rapido 47 & 140 \\
Bellamar & 200 & Bodegón del Gordo & 220 \\
Pequeño Suarez & 190 & El Itsmo & 290 \\
El Criollo & 98 & Los Tres Cerditos & 110 \\
Lai Lai & 98 & El Palacio de la Pizza & 110 \\
Vaca Rosada & 320 & El Quitrín & 210 \\
Steak House & 110 & La Campana & 310 \\
Casa de la Miel & 110 & El Retiro & 190 \\
Terracita Café & 280 & El Dante & 260 \\
Don Alex & El Rancho & 190 \\
Salsa Suárez & 46 & Waco s Club & 150 \\
Vernissage & 46 & Restaurante de Cuatro Palmas & 190 \\
Esquina Cuba & 36 & Varadero 60 & 150 \\
Melaito & 36 & Casa del Chocolate & 76 \\
Vicaria & 120 & Fondue & 76 \\
Nonna Tina & 32 & Barbacoa & 180 \\
\hline
\end{tabular}

Fuente: Elaboración propia.

El histograma de frecuencia (figura 20) confirmó que, las distancias mínimas se encuentran entre los 0 y 200 m. Este resultado confirma los 11 centroides identificados mediante el mapa de calor generado con el QGis.

Figura 20 - Histograma de frecuencia Histograma

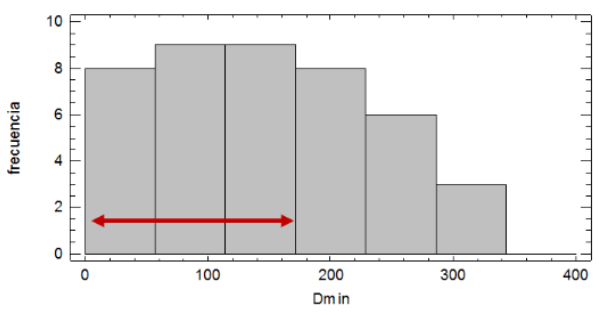

Fuente: Elaboración propia. 
Hasta los 57 metros hay 8 restaurantes, de los 57 a los 114 metros 9 restaurantes y 8 de los 171 metros en adelante (tabla 7). Por tanto, la mayoría de los restaurantes poseen una distancia mínima de uno respecto a otro menor de 200 metros. Este comportamiento sugiere una alta concentración de ofertas en el destino.

Tabla 7 - Frecuencia de las distancias mínimas

\begin{tabular}{llllllll}
\hline Clase & $\begin{array}{l}\text { Límite } \\
\text { Inferior }\end{array}$ & $\begin{array}{l}\text { Límite } \\
\text { Superior }\end{array}$ & Punto Medio & Frecuencia & $\begin{array}{l}\text { Frecuencia } \\
\text { Relativa }\end{array}$ & $\begin{array}{l}\text { Frecuencia } \\
\text { Acumulada }\end{array}$ & $\begin{array}{l}\text { Frecuencia } \\
\text { Rel. Acum. }\end{array}$ \\
\hline \multirow{2}{*}{ menor o igual } & 0,0 & & 0 & 0,0000 & 0 & 0,0000 \\
2 & 0,0 & 57,1429 & 28,5714 & 8 & 0,1860 & 8 & 0,1860 \\
3 & 57,1429 & 114,286 & 85,7143 & 9 & 0,2093 & 17 & 0,3953 \\
4 & 114,286 & 171,429 & 142,857 & 9 & 0,2093 & 26 & 0,6047 \\
5 & 171,429 & 228,571 & 200,0 & 8 & 0,1860 & 34 & 0,7907 \\
6 & 228,571 & 285,714 & 257,143 & 6 & 0,1395 & 40 & 0,9302 \\
7 & 285,714 & 342,857 & 314,286 & 3 & 0,0698 & 43 & 1,0000 \\
& 342,857 & 400,0 & 371,429 & 0 & 0,0000 & 43 & 1,0000 \\
\end{tabular}

Media $=151,209$ Desviación Estándar $=82,8621$

Fuente: Elaboración propia.

Con estos datos se realizó un gráfico de burbujas, a partir del inverso de las distancias mínimas (Idm) reales, obtenidas según:

$$
I d m=\frac{1}{D \min } * 10000
$$

Así, a mayor cercanía mayor tamaño de la burbuja. Se aprecia que existe un solapamiento de unos restaurantes con otros, reafirmándose una vez más la aglomeración existente entre ellos (figura 21).

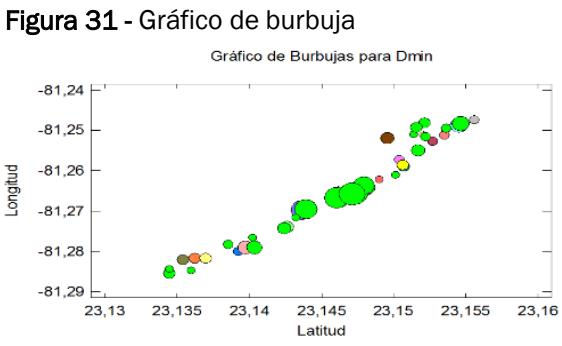

Fuente: Elaboración propia.

\section{Propuestas de reordenamiento o rediseño de la oferta}

Sobre la base del análisis realizado, tanto geográfico como estadístico, de los servicios de restaurantes en el espacio turístico definido como objeto de estudio, se evidenció una deficiente distribución de la localización de las ofertas. Además, existe un desbalance por parte de las ofertas, siendo la comida internacional, el tipo de cocina que prevalece. Los restaurantes no se encuentran ubicados estratégicamente, indicando un déficit en la planificación territorial de acuerdo con Diéguez Matellán (2008); Soulard et al. (2018). Este comportamiento trae como consecuencia la descomercialización, descenso de la rentabilidad y carencia de atractivo para los clientes que optan por comprar Varadero como destino turístico para vacacionar, en correspondencia con Willmer Escobar et al. (2015). Este planteamiento se sustenta en los resultados obtenidos a partir del análisis de densidad y aglomeración.

Se considera por tanto la realización de un reordenamiento o rediseño de la oferta. Si se atiende la primera solución propuesta, resulta más acertado proponer un reordenamiento de los restaurantes en el plano, aunque sería un proceso inversionista costoso para el destino (Estay y Chávez, 2015). Sin embargo, se puede tener en cuenta en el desarrollo de estrategias de planificación territorial (Toro et al., 2015) para la apertura de futuras instalaciones restauranteras.

Resulta entonces más razonable realizar un rediseño de la oferta. Es un proceso inversionista menos costoso y contribuye en gran manera a mejorar la distribución de la oferta en el plano. Hay que tener en cuenta, que existe una carencia de restaurantes de comida criolla y el país debe trabajar constantemente en promover la Auténtica Cuba, el principal slogan presente en la publicidad y promoción como destino turístico a comprar. Partiendo de la observación de los restaurantes en el mapa y su distribución, se propone: 
De la calle 5 a la 13 existe un centroide, donde se aprecian 6 restaurantes, 4 de comida internacional y dos de cocina especializada. Analizando las características en cuanto a infraestructura y diseño de la instalación, es posible rediseñar la oferta en el actual restaurante internacional Casa del Chef a cocina criolla.

De la calle 25 a la 32, se identificó otro centroide. Hay 5 restaurantes, 4 de ellos son especializados y solo uno de comida internacional. Si se tiene en cuenta que el rediseño propuesto va dirigido a incrementar el número de restaurantes de comida criolla y analizando cada uno de estos, se considera que el restaurante que debe rediseñar su oferta es el Steak House. A pesar de ser un restaurante especializado, su comercialización es baja, lo que implica una baja rentabilidad. Como estrategia de comercialización y a su vez de planificación, se puede reestructurar su oferta, cambiándola a comida criolla, crear una nueva imagen del mismo y capturar a los clientes con platos típicos cubanos

De la calle 43 a la calle 49 se identifican 5 restaurantes, de los cuales 3 son de cocina especializada y dos de comida internacional. Se sugiere que, El Bodegón del Gordo debería reformar su oferta, pasar de comida internacional a comida criolla. Este un restaurante privado, se ubica en la zona central donde resultan escasas las ofertas criollas.

Por último de la calle 54 a la 64, zona donde existe una mayor concentración de servicios restauranteros, con un total de 13 restaurantes, 3 de comida criolla, 3 de comida especializada y 7 de comida internacional; se considera el rediseño de su oferta al restaurante El Rancho, el cual posee una infraestructura con elementos típicos cubanos, y está ubicado en la avenida, oportunidad crucial para su comercialización.

El rediseño de las ofertas gastronómicas, no solo incide en la comercialización de las empresas, también contribuye al comercio local generando nuevas de demandas de insumos. Por otro lado, ofrece mayor variedad a los clientes y proporciona un abanico de opciones que inciden en la imagen del destino. Por otro lado, la apertura de nuevos comercios tiene un impacto positivo en la población local como fuente de empleos. Asimismo, el aumento de ofertas típicas redunda en la puesta en valor de las tradiciones y cultura del país, aspecto que en la gastronomía cada vez interesa más a los clientes foráneos, enriquece la oferta comercial y contribuye a la satisfacción de los consumidores.

\section{CONCLUSIONES}

La planificación territorial resulta fundamental en la gestión de los destinos turísticos, toda vez que condiciona su desarrollo futuro e impacta en la satisfacción de los consumidores con los servicios prestados. Los antecedentes metodológicos evidenciaron tres métodos principales para los estudios de localización, el métrico metropolitano, métrico euclidiano y el centro de gravedad (González Becerril, 2004) sin embargo, estos centran su análisis en la localización de nuevas ofertas. Por otro lado, en el turismo la variabilidad y movimiento constante de la demanda complejiza su aplicación (Molina Rodríguez, 2019).

La integración de herramientas tanto geográficas como estadísticas, posibilita una toma de decisiones más efectiva para los problemas de localización, o de distribución en este caso. El análisis estadístico de conglomerados aporta robustez a los resultados y el trabajo con sistemas de información geográficos permite profundizar en el tratamiento y visualización de los datos, en concordancia con Rodríguez Sánchez (2016).

Se destaca el contraste entre la información visual, a partir del trabajo con mapas y el análisis estadístico con las distancias entre instalaciones. De esta forma, es posible identificar aglomeraciones que a simple vista no son detectables. Asimismo, las distancias mínimas entre los servicios, posibilita emitir criterios relacionados con la cercanía, toda vez que una alta concentración en un espacio dado si bien aporta variedad, esta puede verse comprometida cuando se tiene en cuenta el tipo de oferta que se comercializa. Así, los estudios relacionados con la localización deben complementar la ubicación geográfica, con la naturaleza (oferta) de los servicios sujetos a análisis.

En los destinos turísticos, la adecuada planificación de las ofertas se nutre de distintas ramas de la ciencia, donde las decisiones deben fundamentarse en estudios que se corroboren entre sí y preferentemente teniendo en cuenta análisis multivariables (Velazco, 2016), en este caso ubicación geográfica y oferta. Al respecto, cuando se trabaja en espacios urbanos, el trazado de las calles resulta otro aspecto a considerar.

El estudio realizado de la localización de instalaciones ya establecidas, aporta una vía para la gestión de destinos turísticos que una vez alcanzada su madurez, precisan reconfigurarse. Los cambios y modificaciones surgidas durante su evolución, requieren un replanteamiento del diseño original. De esta forma, la investigación ofrece una 
vía para su realización, no solo desde la óptica geográfica, sino también incorporando la dimensión competitiva al análisis. Así, la solución aborda de manera integral el problema de la localización.

Los resultados de la investigación evidenciaron que el surgimiento o proyección de servicios a prestar en un destino, no debe dejarse al azar. Debe ser ordenado territorialmente, siguiendo un plan que garantice, la transmisión de la imagen comercial que se persigue y la satisfacción de los consumidores.

\section{REFERENCIAS}

Alcaide, J., Calero, R. y Hernández, R. (2012). Geomarketing: Márketing territorial para vender y fidelizar más. Esic Editorial: Madrid.

Avellaneda, M. (2014). Sistema de gestión de información geográfica gerencial (webmapping). (Diploma) Ingeniero de Sistemas. UPC, Lima.

Ávila Bercial, R., \& Barrado Timón, D. A. (2005). Nuevas tendencias en el desarrollo de destinos turísticos: Marcos conceptuales y operativos para su planificación y gestión. Cuadernos de Turismo, (15), p. 27-44.

Banerjee, S. (2019). Geomarketing and situated consumers: opportunities and challenges. Proceedings of the 3rd ACM SIGSPATIAL International Workshop on Location-based Recommendations, Geosocial Networks and Geoadvertising, New York, USA. https://doi.org/10.1145/3356994.3366017

Barrado Timón, D. A. (2004). El concepto de destino turístico. Una aproximación geográfico-territorial. Estudios turísticos, 160, p. 45-68.

Batista Sánchez, E., González Ferrer, J. R., González Camejo, I. T., \& Leyva Cardeñosa, E. (2017). Procedimiento para medir la imagen de destinos turísticos. Ciencias Holguín, 23.

Baviera, A., Buitrago, J. y Rodríguez, J. (2013). Un modelo de Geomarketing para la localización de supermercados: diseño y aplicación práctica. Documentos de Trabajo de la Cátedra Fundación Ramón Areces de Distribución Comercial (DOCFRADIS). Universidad de Oviedo: España. Disponible en: http://www.catedrafundacionarecesdcuniovi.es/documentos.php

Blancas Peral, F. J., Guerrero Casas, F. M., \& Lozano Oyola, M. (2009). La localización espacial en la planificación del turismo rural en Andalucía: un enfoque multicriterio. Revista de estudios regionales (84), p. 83-113.

Bote Gómez, V. (1990). Planificación Económica del Turismo. Ed. Trillas, México.

Boullón, R. C. (2006). Espacio Turístico. Ed. Trillas, México.

Carro Paz, R. y González Gómez, D. A. 2012. Localización de instalaciones. Argentina. 25 pp. (monografía). Disponible en: https://www.nulan.mdp.edu.ar

Chascos, C. (2003). El geomarketing y la distribución comercial. Revista Investigación y marketing. 79, p. 6-13.

Chase, R., Aquilano, J., Miller, H., Francis, M., \& Hernández, J. (2005). Administración de Producción y Operaciones. 10 ed. Editorial Mc Graw Hill Interamericana.

Chen, L.-F., \& Tsai, C.-T. (2016). Data mining framework based on rough set theory to improve location selection decisions: A case study of a restaurant chain. Tourism Management, 53, p. 197-206. https://doi.org/10.1016/j.tourman.2015.10.001

Cooper, C., \& Fletcher, J. (2003). Tourism: principles and practice. Essex-England: Longman Group. USA. http://www.bureauenglandtourism.gov

Diéguez Matellán, E. (2008). Contribución a la Planificación de servicios complementarios extrahoteleros en destinos turísticos [doctorado, Universidad de Matanzas Camilo Cienfuegos. Cuba].

Domínguez Machuca, J. A. (1995). Dirección de operaciones: aspectos tácticos y operativos. Ed. Ariel, S.A.

Duarte Pimentel, T. (2016). El método ODIT (Observación, Desarrollo e Ingeniería Turística) y su uso para la planificación estratégica y el desarrollo de los destinos turísticos. Espiga. Universidad Estatal a Distancia San Pedro Montes de Oca, Costa Rica. https://doi.org/10.22458/re.v15i31.1289. http://revistaespiga@uned.ac.cr

Estay, M., \& Chávez, C. (2015). Decisiones de localización y cambios regulatorios. Latin American Journal of Aquatic Research, 43.

Gaithes, N., \& Frazier, G. (2000). Administración de producción y operaciones. Ed. International Thomson. 
Godfrey, K., \& Clarke, J. (2000). The tourism development handbook: a practical approach to planning and marketing. Ed. Burns \& Oates.

González Becerril, M. (2004). Algunos factores de éxito de la industria restaurantera: el caso de un restaurante de la Ciudad de Toluca [maestría, Universidad de Las Américas, Puebla. México].

He, Z., Han, G., Cheng, T., Fan, B., \& Dong, J. (2019). Evolutionary food quality and location strategies for restaurants in competitive online-to-offline food ordering and delivery markets: An agent-based approach. International Journal of Production Economics, 215, p. 61-72. https://doi.org/10.1016/i.ijpe.2018.05.008

Hernández Díaz, A. E. (1985). Planificación Turística: un enfoque metodológico-México. Ed. Trillas, México.

Ivars, J. A. (2003). Planificación turística de los espacios regionales en España. Ed. Síntesis.

Jiménez Moya, G. E., León Companioni, A., Piñero Pérez, P. Y., \& Romillo Tarke, A. (2016). SIGESPRO: Sistemas de Información Geográfica para controlar proyectos. Revista Cubana de Ciencias Informáticas, 10. http://www.redalyc.org/articulo.oa?id=378345292011

Jung, S. S., \& Jang, S. S. (2019). To cluster or not to cluster?: Understanding geographic clustering by restaurant segment. International Journal of Hospitality Management, 77, p. 448-457. https://doi.org/10.1016/j.ijhm.2018.08.008

Kaiser Jr, C., \& Helber, L. E. (1983). Tourism, planning and development. Ed. Diana, México. Disponible en: https://www.cabdirect.org/cabdirect/abstract/19841815120

Krajewski, L. J., Ritzman, L. P., \& Malhotra, M. K. (2002). Administración de operaciones. Ed. Prentice Hall Hispanoamericana.

Latour, P. y Le Floc'h, J. (2001). Géomarketing: Principes, méthodes et applications. Éditions d'Organisation: París.

Lawson, F., \& Baud-Bovy, M. (1977). Tourism and recreation development, a handbook of physical planning. Architectural Press.

Longley, P. A. (2015). Geographic information science and systems. Ed. J. W. Sons.

López Morales, J. S., \& Ortega Ridaura, I. (2016). Presencia de la expansión internacional en la misión y visión de las principales empresas privadas y estatales. Estudios gerenciales, 32(140), p. $269-277$. https://doi.org/10.1016/i.estger.2016.06.005

Medina Argueta, G. D. S., \& Rosado Varela, Á. A. (2014). La planificación turística sustentable desde un enfoque sistémico. Gestión Turística (21), p. 09-32. https://doi.org/10.4206/gest.tur.2014.n21-02

Metters, R., Metters, K. \& Pullman, W. (2006). Successful Service Operations Management. Ed. South-Western Educational Publishing.

Molina S. \& Rodríguez, S. (2019). Planificación integral del turismo: un enfoque para Latinoamérica. Ed. Trillas, México.

Neteler, M., \& Misatova, H. (2013). Open source GIS: a GRASS GIS approach. Ed. S. S. B. Media.

ONEI. (2020). Turismo Internacional. Indicadores seleccionados Enero-Diciembre 2019. Oficina Nacional de Estadísticas e Información. Disponible en: www.onei.gob.cu

Osorio García, M. (2006). La planificación turística. Enfoques y modelos. Quivera, 8. http://www.redalyc.org/articulo.oa?id=40180113

PCC. (2016). Lineamientos de la Política Económica y Social del Partido y la Revolución. Partido Comunista de Cuba VII Congreso del Partido.

Pearce, D., \& Soriano Bello, L. (1988). Desarrollo turístico: su planificación y ubicación geográficas. Ed. Trillas, 168. Disponible en: www.sidalc.net

Rodríguez Sánchez, Y. (2016). Contribución a la planificación de la capacidad en la Atención Primaria de Salud y su incidencia en el nivel de servicio al paciente [tesis de doctorado, Universidad de Matanzas].

Saarinen, J. (2017). Enclavic tourism spaces: territorialization and bordering in tourism destination development and planning. Tourism Geographies, 19(3), p. 425-437. https://doi.org/10.1080/14616688.2016.1258433

Schroeder, R. (2006). Administración de operaciones. Ed. Mc Graw Hill. Interamericana.

Solsona Monzonís, J., \& López Olivares, D. (2012). Factores de localización y desarrollo turístico en el espacio rural de la Comunitat Valenciana. Boletín de la Asociación de Geógrafos Españoles (59), p. 221-244. 
Soulard, J., Knollenberg, W., Boley, B. B., Perdue, R. R., \& Mcgehee, N. G. (2018). Social capital and destination strategic planning. Tourism Management, 69, p. 189-200. https://doi.org/10.1016/j.tourman.2018.06.011

Taylor, F. (2013). Geographic Information Systems: The Microcomputer and Modern Cartography. Ed. Elseiver, Ed.

Tooth, B. (2014). Concepto y clasificación de los destinos [presentación de diapocitivas]. Slideshare. http://es.slideshare.net/

Toro, G., Galán, M., \& Pico, L. (2015). La Planificación Turística Desde El Enfoque De La Competitividad. Turismo y sociedad, 16. https://doi.org/10.18601/01207555.n16.09

Torres Oñate, F., Romero Fierro, J., \& Viteri, M. F. (2018). Diversidad gastronómica y su aporte a la identidad cultural. Revista de Comunicación de la SEECl (44), p. 1-13. https://doi.org/10.15198/seeci.2017.44.1-13

Velazco, M. (2016). Entre el poder y la racionalidad: gobierno del turismo, política turística, planificación turística y gestión pública del turismo. Pasos. Revista de Turismo y Patrimonio Cultural, 14. https://doi.org/10.25145/j.pasos.2016.14.038

Vera Rebollo, J. F., \& Baños Castiñeira, C. J. (2010). Renovación y reestructuración de los destinos turísticos consolidados del litoral: las prácticas recreativas en la evolución del espacio turístico. Boletín de la Asociación de Geógrafos Españoles (53).

Wang, J., \& Yan, X. (2017). How Location Matters in Restaurant Success? PACIS. Disponible en: https://ieeexplore.ieee.org

Willmer Escobar, J., Linfati, R., \& Adarme Jaimes, W. (2015). Problema de localización y ruteo con restricciones de capacidad: Revisión de la Literatura. Revista Facultad de Ingeniería, 24(39), p. $85-98$. https://doi.org/10.19053/01211129.3553. http://www.revistas.uptc.edu.co

Zamorano Casal, F. M. (2002). Turismo alternativo: servicios turísticos diferenciados. Ed. Trillas, México, 336. http://www.sidalc.net

\section{Información de los autores}

\section{Yadrián Arnaldo García Pulido}

Doctor en Ciencias Técnicas. Máster en Gestión turística. Licenciado en Ciencias Alimentarias por la Universidad de La Habana, Cuba. Profesor del Departamento de Turismo y Director de Organización, Planificación y Archivos de la Universidad de Matanzas, Cuba.

Contribución: Concepción de la investigación, análisis de datos y discusión de los resultados.

E-maiL: yagpulido@gmail.com

ORCID: https://orcid.org/0000-0001-5282-0754.

\section{Ismaray Rodríguez Bello}

Licenciada en Turismo por la Universidad de Matanzas, Cuba. Profesora del Departamento de Turismo y Colaboradora de Relaciones Internacionales de la Universidad de Matanzas, Cuba.

Contribución: Revisión de la literatura, colecta de datos y discusión de los resultados.

E-mail: ismaray.bello@umcc.cu

ORCID: https://orcid.org/0000-0002-5681-8106.

\section{Roberto Argelio Frías Jiménez}

Doctor en Ciencias Económicas. Máster en Gestión turística. Licenciado en Economía Política por la Universidad de La Habana, Cuba. Profesor del Departamento de Ingeniería Industrial y Especialista de la Dirección de Calidad de la Universidad de Matanzas, Cuba.

Contribución: Revisión de la literatura, análisis de datos y discusión de los resultados.

E-mail: roberto.frias@umcc.cu

ORCID: https://orcid.org/0000-0002-3809-9283. 